\title{
TRABALHADORES EM SAÚDE MENTAL: CONTRADIÇÕES E DESAFIOS NO CONTEXTO DA REFORMA PSIQUIÁTRICA ${ }^{a}$
}

\author{
Mental health workers': contradictions and challenges in the \\ psychiatric reform context
}

\author{
Trabajadores del área de salud mental: contradicciones y \\ desafíos en el contexto de la reforma psiquiátrica
}

\section{RESUMO}

Este estudo analisa o discurso de trabalhadores, apontando caminhos, dúvidas e incertezas que rondam a constituição da equipe de um serviço comunitário de saúde mental. 0 corpus é composto por entrevistas aplicadas no ano de 2006 a 17 dos 25 trabalhadores de saúde mental que trabalham em um serviço substitutivo de uma cidade da Região Sul do Brasil. 0 dispositivo metodológico que subsidia a sistematização dos dados é o "diagrama axiológico-discursivo", construído a partir dos pressupostos teóricos da Análise Crítica do Discurso. Constata-se que a incerteza operacional que une e fragmenta a equipe, ao mesmo tempo, está relacionada com uma cascata de possibilidades, que se inicia na indefinição operacional dos objetos e instrumentos de trabalho em saúde mental, e termina na dificuldade de identificar quem são os profissionais que devem cuidar da loucura no serviço. Espera-se que este estudo ajude na problematização do movimento de reforma psiquiátrica no contexto brasileiro.

Palavras-chave: Saúde Mental. Reforma dos Serviços de Saúde. Política de Saúde.

\begin{abstract}
This study analyzes the mental health workers discourse, pointing directions, doubts and uncertainties about the formation of the community mental health service team. The corpus consists in interviews applied in 2006 to 17 of 25 mental health workers in a substitutive service in a city in southern Brazil. The methodological device which subsidizes the systematization of the data is the "axiological-discursive diagram", constructed from the Critical Discourse Analysis theoretical framework. It was found that the operational uncertainty that joins the team and its fragments at the same time, is related to a cascade of possibilities, which began operating in the very vagueness of the objects and instruments of work in mental health and ending on the difficulty of identifying who are the professionals who must take care of madness in the service. We hope this study can help in questioning the movement of psychiatric reform in the Brazilian context.
\end{abstract}

Keywords: Mental health. Health care reform. Health policy

\section{Resumen}

Este estudio analiza el discurso de trabajadores, señalando caminos, dudas e incertidumbres que se presentan en el proceso de constitución del equipo de una institución de servicios comunitarios de salud mental. El corpus se compone de entrevistas aplicadas en el año de 2006 a 17 de los 25 profesionales de salud mental que trabajan en un servicio sustitutivo de una ciudad de la Región Sur de Brasil. El dispositivo metodológico que subsidia la sistematización de los datos es el "diagrama axiológico-discursivo", construido a partir de los presupuestos teóricos del Análisis Crítico del Discurso. Se constató que la incertidumbre operacional que une y fragmenta, al mismo tiempo, el equipo está relacionao con una gran variedad de posibilidades, que empieza en la indefinición operacional de los objetos e instrumentos de trabajo en el área de la salud mental, y termina en la dificultad de identificar quienes son los profesionales que deben cuidar de la locura en el servicio. Se espera que este estudio pueda ayudar en la problematización del movimiento de reforma psiquiátrica en el contexto brasileño.

Palabras-Clave: Salud mental. Reforma de los servicios de salud. Políticas de salud

\footnotetext{
'Professor Adjunto da Faculdade de Enfermagem e Obstetrícia da Universidade Federal de Pelotas (Brasil). Doutor em Enfermagem Psiquiátrica pela EERP-USP. Brasil. E-mail: Lbpinho@uol.com.br, ${ }^{2}$ Professor Titular do Departamento de Filologia da Universidade de Almería (Espanha). Doutor em Filologia e Líder do Grupo de Pesquisa ECCO (Estudios Críticos sobre la Comunicación)Espanha. E-mail: amhernan@ual.es, ${ }^{3}$ Professora Adjunta da Faculdade de Enfermagem e Obstetrícia da Universidade Federal de Pelotas (Brasil). Doutora em Enfermagem. Pesquisadora do CNPq. Brasil. E-mail: kantorski@uol.com.br
} 


\section{INTRODUCÃO}

As transformações no contexto da assistência psiquiátrica nos últimos anos têm trazido importantes contribuições para repensar o cuidado psiquiátrico no contexto brasileiro. Com a reforma psiquiátrica, procura-se desconcentrar o olhar sobre a doença, para dar ênfase ao sujeito, suas expectativas, seus projetos de vida, suas relações sociais e sua comunidade. Nesse sentido, a reforma psiquiátrica nasce como um movimento que visa à desconstrução de saberes e práticas cristalizadas no manicômio, um espaço que segrega e exclui com o subterfúgio de "tratar" as manifestações da loucura. ${ }^{1}$

A reforma psiquiátrica também propõe o nascimento de novos dispositivos de tratamento, substitutivos ao manicômio e inseridos na comunidade onde vive o sujeito. No contexto brasileiro, esses serviços são chamados de Centros de Atenção Psicossocial. Esses serviços devem estar articulados, em parceria, com outros serviços de saúde, para que possa dar conta de contemplar as diferentes dimensões da vida humana que vivencia uma situação de sofrimento mental. Nesse caso, os serviços substitutivos nascem como propostas inovadoras de tratamento, reabilitação, cuidado e inclusão, premissas essas pouco existentes nos espaços hospitalares psiquiátricos. ${ }^{2}$

Entendemos que os Centros de Atenção Psicossocial se caracterizam como experiências inovadoras de inclusão e sociabilidade dos sujeitos em sofrimento mental, antes afastados do convívio social por discursos reducionistas e excludentes do louco, da loucura e de suas relações. Além disso, a própria lógica de funcionamento do serviço na comunidade redireciona não somente 0 olhar para o exterior do mesmo, como também para o seu interior, com a transformação de estruturas, processos, contextos, saberes, práticas e, mais do que isso, pessoas.

Esse novo olhar para o fenômeno da loucura e para o louco também exerce influências substantivas no processo de constituição da equipe de trabalhadores de saúde mental. Se no manicômio a equipe era fragmentada, dividida em competências/habilidades específicas ${ }^{3}$, hoje é estimulada a organizar-se de maneira horizontal, compartilhando saberes e práticas, rediscutindo cotidianamente as situações e determinando, em conjunto, as estratégias de intervenção. Dessa maneira, a equipe vai se desfazendo do conjunto de categorias específicas que a representava para formar um novo coletivo, dessa vez organizado de forma interdisciplinar e responsável por atender as diferentes demandas e dimensões que apresenta o sujeito em sofrimento mental.

Mesmo diante de um contexto em transformação, entendemos que a formação da equipe está permeada de desafios, contradições e potencialidades. Esse estudo, nesse sentido, analisa o discurso dos trabalhadores de saúde mental, apontando caminhos, dúvidas e incertezas que rondam 0 processo de constituição da equipe de um serviço comunitário de saúde mental.

\section{O REFERENCIAL TEÓRICO-FILOSÓFICO}

Escolhemos a Análise Crítica de Discurso (ACD) ${ }^{4}$ para analisar o discurso do trabalhador e apontar contradições e desafios no contexto da formação da equipe de saúde mental. A ACD é um referencial fruto de um intenso debate no campo das ciências humanas para ressignificar o conceito e a atuação da linguagem na sociedade.

A linguagem é um elemento essencial para a constituição sócio-histórica dos homens no mundo. Por meio dela é que nos comunicamos, interagimos com a natureza, damos "sentido" à nossa existência e às nossas coisas, construímos conhecimento, constituímos nossa sociedade. A linguagem é produto e produção da vida humana, pela qual somos capazes de persuadir, problematizar, negociar, agir e falar. $^{5}$

0 que torna a linguagem "possível" de ser exercida é exatamente a sua expressão como atividade humana, como acontecimento, como um "devir social". Esses acontecimentos ocorrem por meio das paixões, das misturas e das ações (nesse caso, humanas). 0 acontecimento pertence à linguagem, mantém uma relação essencial com ela. Não existe sentido para "acontecimentos"; eles são o próprio sentido das coisas, a expressão dessas mesmas coisas. No entanto, não é 0 acontecimento que "produz os fatos", mas a linguagem, pois tudo se passa na linguagem e pela linguagem. ${ }^{6}$ Sendo assim, devido à multidimensionalidade da linguagem, toda e qualquer atividade de comunicação possui diferentes sentidos ou significados, cabendo ao analista identificá-los e interpretálos. $^{7}$

A ACD é um dispositivo teórico-filosófico que busca reposicionar o papel da linguagem no interior das relações humanas. Seu enfoque crítico nasceu por ser uma conexão dialética entre os atos da fala, suas repercussões na materialidade social e um método específico para compreendê-las. Com isso, a ACD se constitui em um instrumento de análise das relações dialéticas entre as práticas sociais e as práticas semióticas, incluindo-se, nesse contexto, a própria linguagem. Assim, a linguagem é dialética, e não um sistema fechado sobre si mesmo, uma vez que representa produção/reprodução/formação de realidades sócio-históricas e que se manifestam na forma de signos linguísticos. ${ }^{4}$ 
No contexto da saúde mental, a análise crítica do discurso dos trabalhadores pode evidenciar o caráter producente/contraproducente dos saberes e das práticas nos Centros de Atenção Psicossocial. Entre esses saberes e práticas, destacamos a própria formação da equipe de saúde mental e como ela se organiza no cotidiano para atender às demandas da clientela que busca os serviços cotidianamente.

No discurso sobre a formação da equipe, é possível identificar contradições, desafios e potencialidades, que 0 tornam único e igualmente complexo, capaz de trazer à tona novos (ou velhos) discursos sobre as relações que os trabalhadores com o serviço, com eles mesmos e com a clientela de atendimento. São esses discursos que conferem um caráter dialético à prática dos trabalhadores, que permitem resituar (ou não) o louco e a loucura no cotidiano dos serviços comunitários. Essa realidade resulta em substantiva importância para 0 analista de discurso poder identificar as particularidades, as diferenças, os conflitos, bem como os mecanismos ideológicos e hegemônicos que se deslocam dialeticamente no cotidiano do trabalho das equipes de saúde mental.

\section{O PERCURSO MEDOLÓGICO}

Trata-se de uma pesquisa de abordagem qualitativa. 0 corpus é composto por entrevistas aplicadas a 17 dos 25 profissionais de saúde mental que trabalham em um serviço substitutivo de uma cidade da Região Sul do Brasil e que se dispuseram a participar da pesquisa, desenvolvida no ano de 2006. Foram entrevistados três psicólogos, um enfermeiro, dois terapeutas ocupacionais, um farmacêutico, um psiquiatra, dois assistentes sociais, três auxiliares de enfermagem, um agente de saúde pública, um oficial administrativo, um vigilante e um servente, os quais respondiam aos critérios definidos pela pesquisa (trabalhar há pelo menos seis meses no serviço, estar em efetivo exercício no período de coleta de dados e se dispor a participar da pesquisa).

Foram aplicadas duas perguntas-chave, conforme roteiro previamente estabelecido. As perguntas foram: 1) Fale sobre 0 atendimento no serviço e 2) Fale sobre os fatores que possam contribuir para um melhor funcionamento do serviço. As entrevistas foram gravadas em fitas cassete e, depois de concluídas, encaminhadas a dois digitadores diferentes.

Os dados foram organizados conforme o dispositivo denominado "Diagrama Axiológico-Discursivo". ${ }^{5}$ Essa ferramenta foi desenvolvida no intuito de encontrar certo padrão discursivo nos informantes, ou seja, um "discurso prototípico", que, por ser naturalmente valorativo, já que agrega juízos de valor a comportamentos ou ações humanas, está inserido no âmbito da axiologia. No caso da representação discursiva dos trabalhadores sobre sua própria prática, a aplicação do dispositivo revelou que o discurso está voltado para a "incerteza", a qual revela o padrão ideológico da prática como possuindo limites imprecisos, responsáveis pelos conflitos, pelas dificuldades e pelas contradições. Esse estudo é um recorte do discurso da incerteza, relacionado com a constituição da equipe de saúde mental.

Como o objetivo era poder encontrar um padrão discursivo que revelasse a intenção de todos os informantes, não é necessário reproduzir fragmentos discursivos de todos eles. Optamos por apresentar apenas o discurso mais representativo da dimensão axiológica analisada. No entanto, em função do espaço limitado, não foi possível analisá-lo em sua totalidade. Para isso, recorremos ao uso de fragmentos que descrevessem os aspectos mais importantes da dimensão analisada (a incerteza).

0 projeto foi submetido previamente a avaliação pelo Comitê de Ética em Pesquisa da Faculdade de Medicina da Universidade Federal e Pelotas (UFPel), obtendo parecer favorável ao seu desenvolvimento (Ofício 074/2005). Foi, também, garantido o anonimato dos sujeitos do estudo e respeitados todos os preceitos ético-legais que regem a pesquisa com seres humanos, como é preconizado pelo Ministério da Saúde (Resolução CNS 196/96) e Código de Ética dos Profissionais de Enfermagem (Resolução COFEN 311/2007).

\section{O RESULTADOS E DISCUSSÕES}

No campo da saúde ainda vemos diferentes processos de trabalho centrados em uma lógica em que o modelo biomédico é hegemônico, a especialização parcela o conhecimento, as relações entre os trabalhadores são pautadas na verticalização e na hierarquia institucional e o cuidado é fragmentado, com poucas reflexões sobre o sentido totalizador da vida. Nesse caso, a saúde e o trabalhador vão se alienando, distanciando-se, deixando de lado a valorização, a autonomia e a libertação de sujeitos. ${ }^{8}$

Os trabalhadores em saúde são produto de um sistema de relações, assim como coprodutores deste mesmo sistema. Em um contexto tão complexo como este, marcado pela diversidade de formações, concepções, opiniões e visões de mundo, unir esforços para processar as mudanças necessárias torna-se uma tarefa essencialmente coletiva. Dessa forma, administrar os conflitos, as diferenças e, principalmente, resgatar a singularidade dos atores sociais são desafios importantes para definir o projeto terapêutico e evitar a alienação do trabalhador. ${ }^{9}$ 
A constituição da equipe em uma proposta que visa a ser inovadora também gera incertezas, repercutindo em diferentes dificuldades operacionais do cotidiano. Uma das maiores dificuldades está na convivência entre o profissional mais "novo" e aquele mais "antigo", devido ao fato de os novos serem contratados com vínculo precário e absorvidos pelo serviço com pouca ou quase nenhuma experiência de trabalho em saúde mental:

Então assim, pra termos de avaliação, é importante que a gente tenha uma ideia ... em relação ao serviço e também de alguns fatores que possam contribuir pro melhor funcionamento do serviço. 0 que tu terias a dizer? (Investigador)

Então, eu acho que a equipe... existem as pessoas mais antigas e existe as pessoas novas. Eu não estou dizendo que os antigos são sábios, mas também, nós temos que aprender muito também, mas os novos que tão entrando, eles entram meios perdidos aqui dentro. Então eu acho que eles precisariam de mais orientação de entender essa proposta do CAD. 0 que é técnico de referência? 0 que é o técnico do dia? O que que é o grupo tal? 0 que que é a oficina tal? Como é que faz triagem? Por que tanta pergunta? Por que tem que fazer tantas perguntas? Eu acho que essas pessoas que entram, elas entram muito cruas, e aí entra a questão do perfil. Acho que nem todo o profissional que entra aqui é o que deveria ficar. Porque às vezes ele não tem jeito, ele não gosta, ele não... gosta da proposta, ele não entende a proposta, daí não... e fica porque fica. Porque foi colocado aquie não sai. Mas muitos, alguns profissionais ainda acho que eles não estão no lugar certo, eles poderiam ser aproveitados bem melhor em outro local que não fosse a saúde mental, que não fosse CAPS, então, porque a gente tem essa proposta diferenciada, e... não digo a maioria, alguns não entendem isso, alguns acham que a gente é facilitador, que tá fazendo tudo, ou... ou até a gente acha que faz demais, que tá fazendo demais. Então eu acho que a pessoa que é indicada pra vir pra cá não devia ser uma questão de vaga. Existe a vaga lá. Vou colocar lá, ela deveria ver o perfil mesmo. Se ela tem a condição de trabalhar nesse serviço. $\underline{\text { Às }}$ vezes a pessoa vem aqui pra se tratar, não pra trabalhar. Então fica um pouco complicado. (Trabalhador)
0 município estudado tem uma política de contratação de pessoal baseada na abertura de processos seletivos especiais, para selecionar funcionários temporários que superem, de imediato, a falta de trabalhadores em áreas específicas da saúde. Esse procedimento faz com que exista constantemente, no serviço, um conflito entre os profissionais mais recentes ou "novos" (geralmente provisórios) e aqueles que já possuem experiência prévia de trabalho no serviço ou mais "antigos" (geralmente concursados). Esse conflito não é preferencialmente causado pela convivência entre os dois grupos distintos de atores, mas mediado pela dificuldade de sistematização de conhecimentos e práticas em saúde mental que exigem certa experiência prévia, acompanhamento sistemático ou treinamento específico.

Para fortalecer essa ideia de que o "novo" traz prejuízos para a prática do serviço, há o uso de figuras metafóricas, elementos metadiscursivos e algumas estruturas argumentativas (perguntas retóricas).

Na primeira situação, o trabalhador inicia sua argumentação com o metadiscurso "Então...", que mostra que o "novo" é incorporado sem a devida preparação (treinamento) no interior do serviço ("Então, eu acho que a equipe"). 0 falante faz questão de frisar que a equipe se sente prejudicada com a entrada de novos profissionais recentemente contratados, pois deve atender suas demandas e administrar as demais atividades inerentes à sua competência no cotidiano.

Um metadiscurso é uma estrutura linguística que está imersa nos contextos sociais como mecanismo fundamental para desvendar as interações sociais e seus efeitos de sentido. Entretanto, um metadiscurso só adquire um significado quando incorporado a um contexto específico, em que leitor e escritor (ou entrevistador e entrevistado no caso de discursos orais como este) constroem, juntos, a materialidade ideológica da linguagem. ${ }^{10}$

No entanto, para não causar impressões equivocadas ou negativas, o trabalhador procura um novo elemento metadiscursivo que funcione como ferramenta reparadora para aquilo que emite, para evitar falhas ou truncamentos no processo comunicacional. Quando afirma "não estou dizendo que os antigos são sábios", o falante procura resgatar "novos" e "velhos" como membros de uma única equipe, equiparando a necessidade de aperfeiçoamento técnico para ambos. No caso dos mais novos, o treinamento é para suprir o despreparo, enquanto que, para os mais velhos, serve como adaptação e definição de novas estratégias, em função do modo cambiante de fazer saúde mental no interior do CAPS.

Do ponto de vista discursivo, esse metadiscurso é uma maneira de mostrar que o falante (o mais velho) possui 
consciência do mal-estar que pode provocar à imagem do outro (o mais novo). Caso não houvesse a reparação, o mais novo seria classificado como um inexperiente, um atrapalhado, e o antigo como um expert, que precisa modificar sua rotina diária para dar conta de atender às demandas do funcionário recentemente contratado.

A reparação (remedy) é um conceito introduzido por Erving Goffman para designar uma necessidade do emissor de evitar os problemas no cotidiano conversacional. A imagem (face) de uma pessoa projeta na outra uma série de opiniões. Todo sujeito sente a necessidade de ser apreciado pelo outro com quem está em relação, ser compreendido e não ser molestado. Para tanto, o autor denominou "imagem positiva" a necessidade de ser apreciado pelo interlocutor e de "imagem negativa" a necessidade de não ser prejudicado por ele. ${ }^{11}$

Em uma interação social, que inclui a comunicação verbal, os participantes procuram constantemente esforçar-se para buscar a estabilidade em suas relações com os demais. No entanto, esforçar-se para manter uma imagem social (face work) não deve ser usado como elemento que possa violar a imagem do outro. Nesse caso, o que pode ser considerado uma imagem positiva para um indivíduo, pode ser negativa para o outro. Assim, todo sujeito em interação deve preocupar-se com seus próprios limites e com os limites do outro, imprecisos por natureza, devendo utilizar mecanismos que possam diminuir os efeitos de tais "atos ameaçadores da imagem", para preservar o contexto interacional. ${ }^{11}$

0 trabalhador que ameaça a imagem do outro, em um contexto onde se busca a interação, estaria ultrapassando as fronteiras que delimitam o respeito, a cortesia, a própria afetividade e o conhecimento sobre a singularidade humana. Em um contexto em que as dúvidas imperam sobre as certezas, como é na saúde mental, um profissional novo precisa ser inserido e acolhido como se fosse uma nova força produtiva no contexto da instituição. Apesar de não saberem por onde começar, o que fazer ou como fazer, todo trabalhador precisa sentir aquele interesse genuíno que aproxima, que compreende suas limitações, mas que busca desenvolver suas potencialidades. Em um trabalho interdisciplinar, a competência de um sujeito pode não ser a de outro, e a interlocução entre eles é que move o serviço em direção à autonomia, à satisfação e ao prazer com o trabalho que se faz.

A questão do despreparo do profissional novato é encarada pelos trabalhadores como um desafio na organização metodológica das práticas do serviço. Para mostrar qualitativamente a necessidade de um treinamento para os novos funcionários, para não prejudicar o funcionamento do serviço, o discurso é marcado com figuras metafóricas e perguntas retóricas.
Na primeira situação, o profissional novato "fica meio perdido" não no sentido literal, mas por não saber o que fazer quando ingressa em um contexto totalmente diversificado. Isso representa o juízo de valor que o trabalhador mais antigo (experiente) tem sobre a condição do novato (inexperiente). Em meio a essa dificuldade de adaptar-se às rotinas, parece surgir a necessidade do treinamento, invocada na sequência da fala por meio de perguntas retóricas do tipo: "0 que é técnico de referência? 0 que é o técnico do dia? 0 que que é o grupo tal? 0 que é a oficina tal? Como é que faz triagem? Por que tanta pergunta? Por que tem que fazer tantas perguntas?"

Às vezes, uma pretensão resulta mais convincente no contexto da enunciação quando uma argumentação é transformada em pergunta retórica. Esse tipo de pergunta convida aquele que formula a dar uma resposta, no entanto ele já possui a sua resposta. Em linguística, existem diferentes explicações para o fato de as perguntas retóricas terem maior capacidade argumentativa do que a própria afirmação em si. Primeiramente, é possível que elas sejam usadas para associar argumentos consistentes, já que os receptores inferem que eles são verdadeiros. Nesse caso, a pergunta retórica aumentaria o poder de persuasão da linguagem, sem importar qual seja a força do argumento. Na segunda hipótese, as perguntas retóricas extrairiam juízos de valor dos receptores, que prestariam maior atenção ao argumento apresentado. Se ele é sólido, ou seja, convincente do ponto de vista discursivo, o receptor atribuirá um juízo mais positivo à pergunta retórica do que ao argumento original que a criou..$^{12}$

Como as perguntas retóricas conduzem a juízos valorativos, logo depois de escutá-la, um receptor geralmente ignora o argumento anterior. Nesse caso, se o receptor chegar a alguma conclusão, será por meio das perguntas formuladas, e não precisamente pelos argumentos iniciais. É possível perceber, então, que as perguntas retóricas posicionadas após o argumento aumentam o poder de persuasão da mensagem, enquanto aquelas posicionadas anteriormente tendem a funcionar de modo inverso, ou seja, anulando o poder de persuasão. $^{12}$

No discurso do trabalhador, o argumento que gera as perguntas retóricas é o fato de que o novo deve ser treinado porque é despreparado para o trabalho em saúde mental. Ao ser complementado pelas perguntas retóricas, nota-se um deslocamento de sentido, em que a própria pergunta assume a centralidade no contexto do discurso. É dizer que o detalhamento, ou seja, o "programa de capacitação" do funcionário mais novo é mais importante do que o próprio argumento de que ele precisa ser treinado, o que também 
causa mais impacto na mensagem transmitida. Isso evidencia o quanto os trabalhadores ainda resistem ao "novo" e aos desafios trazidos com ele, preferindo manter a inovar as rotinas institucionais.

0 novato no serviço também é entendido como um despreparado e um prejuízo para a equipe. Isso aparece por meio de uma relação, onde existe uma linguagem metafórica e metonímica atuando em conjunto.

Quando há referência ao novato como um "despreparado", constrói-se uma relação entre "pessoa/ alimento", mediada por uma linguagem metafórica ("cru/ cozido") - que revela a inexperiência - e também por uma linguagem metonímica ("verde/maduro") - que revela 0 prejuízo à equipe.

Em uma analogia ao contexto original, alimentos que se encontram "crus" geralmente sofrem três caminhos distintos: ou eles precisam ser preparados, o que eleva o tempo de cozimento, ou eles não são utilizados de imediato até que amadureçam, ou eles são desprezados por outro alimento mais aceitável. Realizando uma comparação com a saúde mental, entre desprezar um profissional e deixá-lo inoperante, uma das ofertas mais próximas de uma proposta inclusiva (não somente para o usuário) seria compreender a falta de experiência dele e prepará-lo para o trabalho (capacitação). Até porque 0 funcionário nem sempre é selecionado pelos profissionais do serviço, mas "indicado" por uma gestão que, às vezes, está mais preocupada com o perfil quantitativo de funcionários do que com o investimento na formação qualitativa dos trabalhadores em suas práticas.

Para garantir o avanço das discussões da reforma psiquiátrica no contexto brasileiro, e não reduzi-la à simples abertura de novos (e mais) serviços, é necessário possuir um quadro de profissionais que defenda modelos de atendimento distintos dos anteriores. Para aqueles que não participaram da luta militante e têm dificuldades em transportar novos conhecimentos para o interior do serviço, resta, como tendência inicial, repetir o referencial aprendido anteriormente. Para não cair na contramão da reforma, pensar na formação permanente da equipe é importante, mas não parece suficiente face à complexidade do trabalho com a loucura. É necessário desafiar a clínica do serviço e a clínica da equipe para superar as imprecisões, o que gera um novo campo, propício às experimentações e produções de novos saberes e fazeres. ${ }^{13}$

Enquanto isso não acontece, o "novo" no serviço vai sendo comparado a um funcionário despersonificado, que não pode ser chamado de trabalhador porque não trabalha (naquele sentido materialista a anteriori explorado), já que "presta serviços" em função do interesse específico do governo, não das comunidades. Não pode ser considerado um ator social, porque vai vendo seu conhecimento ser institucionalizado por uma dinâmica burocrática que o absorve. Torna-se um ser dissociado de si mesmo, que não pode se comprometer porque possui vínculo precário, que não reinventa o cotidiano porque fica sem estímulos (tanto da gestão, como dos trabalhadores), e que não processa transformações porque está alienado. Enfim, um ser inanimado, comandado e constituído na forma de um "sujeito assujeitado". ${ }^{14}$

A manutenção de uma ideologia derivada do controle estrutural efetuado pelo governo municipal vai mostrando 0 quanto a prática em saúde mental (já incerta) vai sendo submetida à rigidez e à pouca possibilidade de trocas no microespaço. Desse modo, fica difícil reposicionar as relações hegemônicas no interior do serviço, e o resultado produzido pode ser uma prática discursiva marcada pela lamentação, pela desmotivação e pela revolta. Aqui entraria a questão do perfil do trabalhador, nem sempre aquele desejado ou selecionado pelo serviço, mas o imposto pela administração municipal, gerando mais inquietação e incertezas sobre o futuro das práticas.

Do ponto de vista pragmático, se existe uma relação diretamente proporcional entre o novato e seu ingresso na instituição, essa relação está marcada pela ausência de perfil para trabalhar em saúde mental. Do ponto de vista discursivo, essa relação é mediada pelo uso de advérbios/adjetivos intensificadores, graduadores de intensidades, que vão redesenhado os processos de atribuição de juízos de valor pela imprecisão ou generalização dos processos ou pessoas.

Vamos pensar no ingresso do trabalhador no serviço. Inicialmente, o falante procura mostrar a preocupação com o estabelecimento do perfil, ao indicar que o novato entra "muito cru". Em uma escala de valoração, o "muito cru" situa-se acima do "cru", o que chama a atenção do receptor pela necessidade de fortalecer a potência do enunciado. A representação da falta de preparo técnico-teórico pode explicar certa rejeição do novato no interior das práticas pelos trabalhadores mais antigos, não somente pela sua "indicação" pela gestão, mas porque acrescenta uma nova responsabilidade dentre tantas outras que a equipe já possui.

Já no interior do serviço, inicia-se um jogo dialético que dá origem às diferentes intensidades de valorações. Há uma alternância entre singular e plural organizada em declínio, iniciando em "muitos" trabalhadores e terminando em "alguns" sem perfil. Essa gradação entre "muitos" - que dá noção de generalidade - e "alguns" - que dá a ideia de particularidade - é explicável pelo ponto de vista da necessidade de preservar a constituição da própria unidade da equipe. No entanto, aos 


\section{Trabalhadores de sáude mental:contradições e desafios}

Pinho LB, Hernández AMB, Kantorski LP

poucos o "muitos" vai dando espaço somente aos profissionais que não estão "no lugar certo", que posteriormente vai cedendo lugar à "aquela pessoa indicada", em uma tentativa de reduzir o espectro de profissionais que não possuem perfil, para não prejudicar a imagem social da equipe e da própria instituição.

Há uma relação clara no discurso do entrevistado de que um profissional precisa aliar perfil e conhecimentos prévios do sistema para trabalhar no CAPS. Um profissional que não viesse "cru" seria dispensado de treinamento. Logo, quando dispensado do treinamento, não sobrecarregaria a equipe. Entretanto, aqui cabem questionamentos: em uma prática altamente mutante, em que o cotidiano ressignifica o espaço das relações, dos saberes e das atitudes, existiria um profissional com perfil preestabelecido e que não viesse despreparado? Se já existe uma dificuldade dentro da atenção psicossocial para estabelecer fronteiras precisas de atuação profissional, onde encontrar esse "supertrabalhador" que venha preparado, entendendo o funcionamento do serviço e que se adapte facilmente à realidade?

Além das questões que envolvem a constituição da equipe e sua organização, existia uma tendência em considerar como "membro nato" aquele que participava das discussões e do atendimento no cotidiano. Isso ocasionava uma nova fragmentação na equipe de saúde mental, que, se antes estava dividida entre "novos" e "antigos", agora se manifesta pela "introdução" de categorias até então não contempladas:

A questão dos nossos guardas é... a equipe de serventes, da equipe da cozinha. Acho que é uma falha nossa, a gente não colocar eles mais junto conosco [...] falou muitas vezes: "Ah, vai ter que participar da reunião.", "Ah..." não sei o quê... Mas sempre tem alguma coisa que eles não podem participar das reuniões, nem a própria assembléia eles participam. E eu vejo que eles são peça. fundamental na equipe, eles tão assim porque eles ficam é... circulando por aí. Conversam com um, e conversam com outro usuário, e a gente vê que eles tão dando algum palpite, alguma orientação, eles acham que eles não fazem isso, mas na verdade eles fazem. Claro, a gente vê eles falando... "Como que foi aquilo? Aquele negócio deu certo? Conseguiu falar com aquela pessoa? Resolveu tal problema?". Então, eles tão lidando. Com ele, mas eles não participam das nossas reuniões. Então eu acho isso uma falha_... Então eles falam que eles são profissionais terceirizados. Principalmente a parte dos guardas;: as serventes nem tanto, porque elas estão conosco, há um bom tempo. Mas os guardas que mudam mais, eles ficam terceirizados e eles não... não querem. Não faz falta também eles participarem das nossas reuniões ou de algumas atividades que a equipe solicitou, então... Teve uma vez que a gente precisou de um deles pra fazer grupo de 8 e o guarda quase que surtou. Porque ele disse que aquilo ele não fazia, ficou assustado, e depois aquilo mexeu um monte com ele. Mas isso também eu acho que é por falta de orientação. Assim que eles entram no serviço chama: "Oh, aqui acontece isso. Pode acontecer esse tipo de crise, a gente pode precisar de você pra fazer o grupo de oito". Explicar o tal grupo de oito, eu acho que é uma falha da equipe. É... mas ao mesmo tempo a gente perguntou quem é que tem que fazer isso. Somos nós que temos que fazer isso, ou é a coordenação, ou é administrativo. Então a gente fica se... se questionando sobre isso também. Quem tem que fazer essa parte. (Trabalhador)

0 discurso tende a fragmentar a unidade da equipe em "nossos guardas", a "equipe de serventes" e a "equipe da cozinha". Embora considerados como "peça fundamental", são reconhecidos contraditoriamente pelo discurso como figurantes, uma equipe complementar, porque "também" (no sentido de "adicionalmente") devem ser lembrados a participarem das atividades do serviço. Logo, a equipe principal seria aquela formada pelos profissionais de nível médio e superior, protagonistas, responsáveis pelo atendimento direto, enquanto que os guardas, serventes e auxiliares de limpeza seriam os figurantes, o pessoal de apoio. Isso parece significar que ainda sobrevive no interior do discurso dos trabalhadores certo resquício originado do modelo ambulatorial de organização, que fragmenta o saber nascido da interação com todos para, diametralmente, privilegiar as competências profissionais especíicas de cada formação disciplinar, de maneira vertical.

Do ponto de vista discursivo, esse "resquício" pode ser explicado porque o discurso cria novas realidades, mas tambémé capaz de reproduzir, no tempo e no espaço, as regularidades e dispersões de uma dada sociedade, o que se denomina de "formaç̃̃es discursivas". ${ }^{15}$ De acordo com o autor, cada formação discursiva é capaz de constituir um saber, dada a sua permanência e influência histórico-social. Assim, não há saber sem uma prática discursiva definida, mas toda a prática discursiva pode ser definida pelo saber que ela forma.

0 servente, o guarda ou o auxiliar de limpeza são profissionais que, conforme o discurso, ainda não parecem ter garantido seu lugar no projeto terapêutico da instituição. 
Primeiramente, existe uma intenção de incorporá-los ao serviço como agentes de transformação das práticas, uma vez que acompanham diariamente a rotina do serviço e interagem diretamente com os usuários, questionando e opinando sobre a vida dos mesmos. Ao mesmo tempo, parecem funcionar como funcionários de apoio, figurantes, pois o protagonismo ficaria a critério de uma equipe já previamente estabelecida, responsável pelos atendimentos diretos da clientela.

Finalmente, é possível notar que a incerteza que une e fragmenta a equipe, ao mesmo tempo, está relacionada com uma cascata de possibilidades, que se inicia na indefinição operacional dos objetos e instrumentos de trabalho em saúde mental, etermina na dificuldade de identificar quem são os profissionais que devem cuidar da loucura nos serviços substitutivos de saúde mental. Isso significa que os trabalhadores tentam assimilar as incertezas trazidas pelas mudanças no processo de trabalho na área, sendo um desafio interessante para problematizar os serviços, as práticas, os saberes e as pessoas que fazem o dia-a-dia da reforma psiquiátrica no contexto brasileiro

\section{CONSIDERAÇÕES FINAIS}

Como pôde-se observar, a reforma psiquiátrica vem trazendo inúmeros desafios para os processos de trabalho em saúde mental. Em um ritmo dialético, os trabalhadores vem sendo tensionados a pensar que a busca pela certeza absoluta para a sua prática e para o seu modo de organização em equipe nem sempre parece dar respostas concretas às complexidades dos serviços e das ações de saúde mental focalizadas na comunidade.

Esperamos que este estudo possa ajudar na problematização do movimento de reforma psiquiátrica e dos novos dispositivos de cuidado no campo da saúde mental, complexos por natureza e que desafiam, dia-a-dia, os trabalhadores, seus saberes, suas realidades e seu modo de operar com a loucura no cotidiano de sua prática.

\section{REFERÊNCIAS}

1. Santos ACCF. Referencial de cuidar em enfermagem psiquiátrica: um processo de reflexão de um grupo de enfermeiras. Esc Anna Nery Rev Enferm 2009 jan; 13(1): 51-55.

2. Ministério da Saúde (BR). Saúde mental no SUS: os Centros de Atenção Psicossocial. Brasília (DF); 2004.

3. Lougon M. Psiquiatria institucional: do hospício à reforma psiquiátrica. Rio de Janeiro(RJ): FIOCRUZ; 2006.
4. Fairclough N. Discourse and social change. $11^{\mathrm{a}} \mathrm{ed}$. Cambridge: Polity Press; 2006.

5. Pinho LB. Análise crítico-discursiva da prática de trabalhadores de saúde mental no contexto social da reforma psiquiátrica [tesede doutorado]. Ribeirão Preto(SP): Escola de Enfermagem, Universidade de São Paulo; 2009.

6. Deleuze G. Lógica do sentido. $5^{\text {a }}$ ed. São Paulo(SP): Perspectiva; 2000.

7. Van Dijk TA. El discurso del discurso. In: Van Dijk TA, organizador. El discurso como estructura y proceso. $3^{\mathrm{a}}$ ed. Barcelona(ES): Gedisa; 2006. p.21-66.

8. Pinho LB, Santos SMA, Kantorski LP. Análise do processo de trabalho da enfermagem na unidade de terapia intensiva. Texto\&Contexto Enferm 2007 out/dez; 16(4): 703-11.

9. Campos GWS. Considerações sobre a arte e a ciência da mudança: revolução das coisas e reforma das pessoas, o caso da saúde. In: Cecílio LCO, organizador. Inventando a mudança na saúde. $3^{\mathrm{a}}$ ed. São Paulo (SP): Hucitec; 2006. p.29-87.

10. Moraes LSB. 0 metadiscurso em artigos acadêmicos: variação intercultural, interdisciplinar e retórica [tese de doutorado]. Rio de Janeiro (RJ): Programa de Pós-Graduação em Letras/ PUC Rio de Janeiro; 2005.

11. Goffman E. Representações do eu na vida cotidiana. Petrópolis (RJ): Vozes; 1985.

12. Renkema J. Introducción a los estudios sobre el discurso. Barcelona (ES): Gedisa; 1999.

13. Furtado JP, Campos RO. A transposição das políticas de saúde mental no Brasil para a prática nos novos serviços. Rev Latinoam Psicopat Fund 2005 jan; 8(1): 109-22.

14. Possenti S. Dez observações sobre a questão do sujeito. Linguagem em (dis)curso. Tubarão, 2003; (n. esp): 27-35.

15. Foucault M. Arqueologia do saber. $7^{\mathrm{a}}$ ed. Rio de Janeiro: Forense Universitária; 2005

\section{NOTAS}

${ }^{a}$ Recorte de tese de doutorado intitulada "Análise crítico-discursiva da prática de trabalhadores de saúde mental no contexto social da reforma psiquiátrica", apresentada à Escola de Enfermagem de Ribeirão Preto, em 2009, para a obtenção do título de Doutor em Enfermagem Psiquiátrica. 